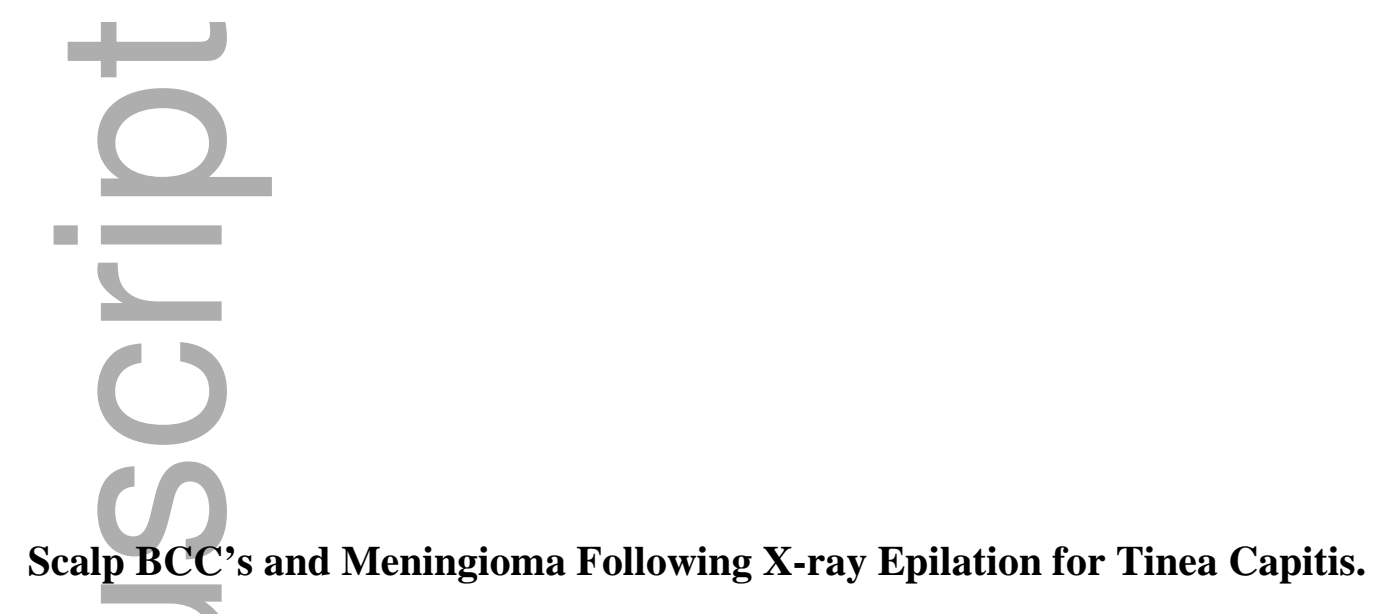

Running title: Scalp BCC's after tinea x-ray treatment

Authors: Lauren Anderson, ${ }^{1}$ Michelle SY Goh, ${ }^{1}$ Christopher J McCormack. ${ }^{1}$

\title{
Affiliations:
}

${ }^{1}$ Department of Dermatology, Peter MacCallum Cancer Centre, Melbourne, VIC

Corresponding Author:

Dr. Lauren Anderson

Peter MacCallum Cancer Centre

Melbourne

Ph: 04151837893

Email: lauren.anderson2208@gmail.com

\section{Author Statements:}

This paper has not been published or submitted elsewhere

This is the author manuscript accepted for publication and has undergone full peer review but has not been through the copyediting, typesetting, pagination and proofreading process, which may lead to differences between this version and the Version of Record. Please cite this article as doi: $10.1111 /$ ajd.12950

This article is protected by copyright. All rights reserved 
All authors have contributed equally

All authors are in agreement with the content of the manuscript

There has been no financial support, conflict of interest.

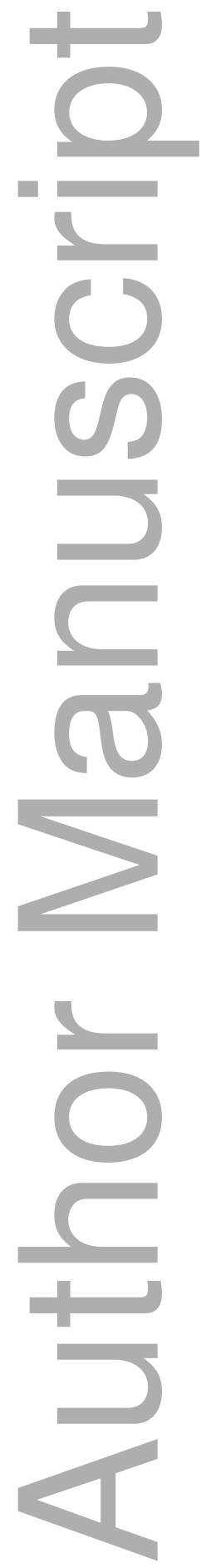


DR. LAUREN ANDERSON (Orcid ID : 0000-0002-3934-7517)

Article type : Case Letter

Scalp BCC's and Meningioma Following X-ray Epilation for Tinea Capitis.

Before the discovery of griseofulvin in the late 1950's, approximately 200,000 children worldwide were treated with x-ray roentgen epilation for epidemic tinea capitis. ${ }^{1}$ Studies on long term effects of radiation in this cohort revealed associations with increased rates of basal cell carcinomas (BCC's), as well as malignancies of the brain, parotid, bone and thyroid.

A 74 year old female Italian immigrant presented to our clinic for management of three biopsy proven nodular scalp BCC's. She was noted to have four more pigmented scalp lesions suspicious for BCC's as well as generalised alopecia for which she wore a wig (figure 1). Past history included a fronto-parietal meningioma diagnosed in 2009 and a period of $\mathrm{x}$-ray epilation for tinea capitis in 1951 at 7 years of age. Her older sister concurrently underwent $x$-ray treatment for tinea capitis at 9 years of age and in 2006 was diagnosed with a recalcitrant meningioma. She, however has had no diagnosed sealp BCC's. Another 67 year old Italian immigrant presented with a nodular scalp BCC after having multiple scalp BCC's excised over the preceding 16 years. Similarly, her history of radiation treatment for tinea capitis in Italy as a child is likely a predisposing factor. She has no other known malignancies.

Radiotherapy for tinea capitis is now a well-recognised risk factor for BCC development with an incidence four times greater than in control groups. ${ }^{1}$ A dose dependent relationship and a high prevalence of multiple, recurrent BCCs has been suggested, as well as an inverse relationship between $\mathrm{BCC}$ risk and age at radiation exposure. Although nodular BCC is the predominant subtype in irradiated patients, there is a relatively high proportion of infiltrative/morpheaform histology and a high frequency of stromal fibroplasia, associated with aggressive growth variants of sporadic BCCs. ${ }^{2}$ There are no genetic differences in p53 and PTCH genes in radiation induced versus sporadic BCCs, but mitochondria D-Loop D310 mutation rate is associated with higher radiation doses in subjected patients. ${ }^{3}$

Ionising radiation is the only proven causative risk factor for the development of meningioma, even at low doses. It is associated with earlier age at diagnosis, higher prevalence of calvarial tumours and a higher proportion of multiple meningiomata. ${ }^{4}$ 
Consistent with the reported literature ${ }^{1-2}$, in our first case, the interval between irradiation and onset of BCCs was approximately 63 years and meningioma diagnosis was 55 years. It was not possible to determine total dosage of ionising radiation administered to our patients, but the mean dose for the total field reported by other authors ranges between 1-6 Gy, with a mean dose of 1.5Gy.

Australian dermatologists should be aware of radiation epilation for tinea capitis as a risk factor for earlier development of multiple, more aggressive scalp BCC's, particularly in our large immigrant population. They require prompt recognition and surgical management or consideration of systemic treatment such as Hedgehog pathway inhibitors. ${ }^{5}$ It is important to be aware of the other associated tumours, in particular intracranial neoplasms, and investigate for them if clinically indicated.
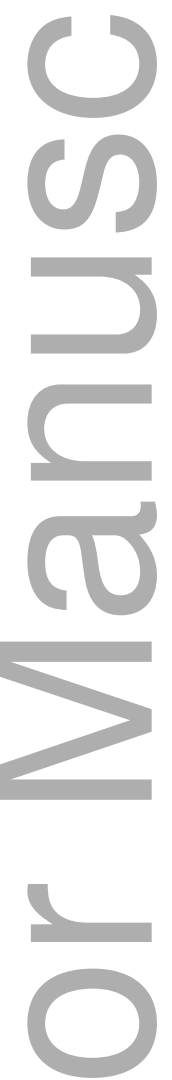

\section{References}

1. Caccialanza M, Piccinno R, Brambati M. Relapsing meningiomas and multiple basal cell carcinomas after x-ray epilation for tinea capitis. Int J Dermatol. Wiley/Blackwell (10.1111); $2012 \mathrm{Jul} ; 51(7): 880-1$.

2. Oshinsky S, Baum S, Huszar M, Debby A, Barzilai A. Basal cell carcinoma induced by therapeutic radiation for tinea capitis-clinicopathological study. Histopathology. 2nd ed. Wiley/Blackwell (10.1111); 2018 Jul;73(1):59-67. 
3. Boaventura P, Pereira D, Mendes A, Batista R, da Silva AF, Guimarães I, et al. Mitochondrial D310 D-Loop instability and histological subtypes in radiation-induced cutaneous basal cell carcinomas. J Dermatol Sci. 2014 Jan;73(1):31-9.

4. Sadetzki S, Flint-Richter P, Ben-Tal T, Nass D. Radiation-induced meningioma: a descriptive study of 253 cases. Journal of Neurosurgery. 2002 Nov;97(5):1078-82.

5. Tauber G, Pavlovsky L, Fenig E, Hodak E. Vismodegib for radiation-induced multiple basal cell carcinomas (BCCs) of the scalp. J Am Acad Dermatol. 2015 Nov;73(5):799-801.

\section{Figure legend:}
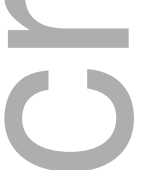

Figure 1: Multiple pigmented scalp BCC's as well as permanent generalised alopecia likely as a result of radiation epilation for tinea capitis.

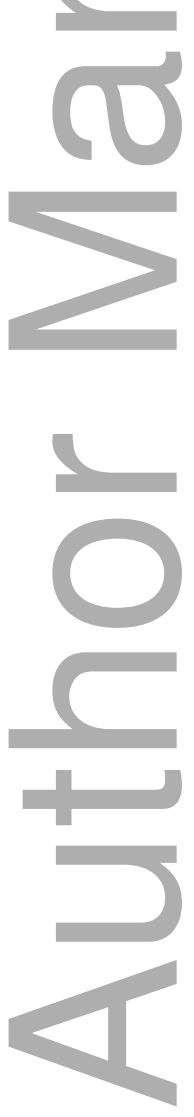




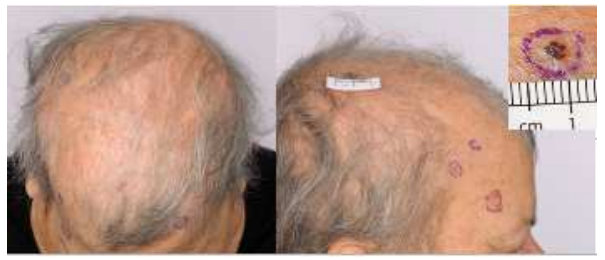

ajd_12950_f1.tiff
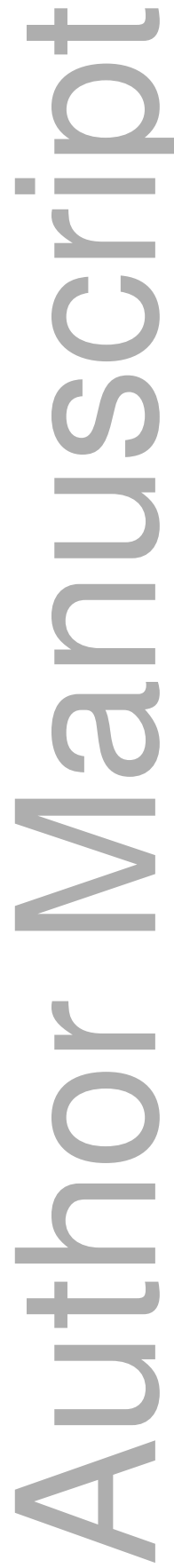


\section{University Library}

\section{- M M I E E R VA A gateway to Melbourne's research publications}

Minerva Access is the Institutional Repository of The University of Melbourne

Author/s:

Anderson, L;Goh, MSY;McCormack, CJ

Title:

Scalp BCC's and meningioma following X-ray epilation for tinea capitis

Date:

2019-05-01

Citation:

Anderson, L., Goh, M. S. Y. \& McCormack, C. J. (2019). Scalp BCC's and meningioma following $X$-ray epilation for tinea capitis. AUSTRALASIAN JOURNAL OF DERMATOLOGY, 60 (2), pp.149-150. https://doi.org/10.1111/ajd.12950.

Persistent Link:

http://hdl.handle.net/11343/285069 